\title{
Levantamento de raças do agente causador do míldio da alface no Estado de São Paulo em 2012 e 2013
}

\author{
Renata de Castro Nunes ${ }^{1 *}$, Renata Castoldi ${ }^{1}$, Rafaelle Fazzi Gomes ${ }^{1}$, Dora Enith Tobar-Tosse ${ }^{1}$, Leila Trevisan Braz ${ }^{1}$
}

${ }^{1}$ UNESP/FCAV - Departamento de Produção Vegetal, Via de Acesso Prof. Paulo Donato Castellane, s/n - 14884900- Jaboticabal, SP.

Autor para correspondência: Renata de Castro Nunes (renatacastronunes@gmail.com)

Data de chegada: 14/11/2014. Aceito para publicação em: 26/05/2015.

$10.1590 / 0100-5405 / 2057$

\section{RESUMO}

Nunes, R.C.; Castoldi, R.; Gomes, R.F.; Tobar-Tosse, D.E.; Braz, L.T. Levantamento de raças do agente causador do míldio da alface no Estado de São Paulo em 2012 e 2013. Summa Phytopathologica, v.42, n.1, p.53-58, 2016.

A alface é, entre as hortaliças folhosas, a mais importante economicamente para o Brasil. No inverno, com baixas temperaturas e com molhamento foliar, o míldio da alface, doença causada pelo agente etiológico Bremia lactucae, ocorre em praticamente todas as regiões de cultivo desta hortaliça, sendo considerada uma das doenças foliares mais severas da cultura. O objetivo deste trabalho foi identificar as raças de B. lactucae no ano de 2012 e 2013 que ocorreram nas principais regiões produtoras do Estado de São Paulo, como: Ribeirão Preto, Jaboticabal, Pirangi, Catanduva, São José do Rio Preto, Atibaia, Salesópolis, Biritiba Mirim, Mogi das Cruzes, Campinas, Itapira, Mogi Mirim, Cândido Mota, Presidente Prudente, Echaporã, Assis, Marília, Botucatu e Bauru. Durante o mês de julho/agosto de 2012 e 2013, coletaramse amostras de folhas de alface com sintomas de míldio, sendo que, em cada amostra coletada, as estruturas do patógeno referiram-se a um isolado. Os esporângios foram multiplicados na cultivar suscetível Solaris, com posterior inoculação nas cultivares diferenciadoras, realizando-se as avaliações no $12^{\circ}$ dia do aparecimento da primeira esporulação na cultivar suscetível 'Green Tower' (Dm-0), conforme o código "Sextet". Em 2012, foi determinado dois novos códigos, identificando duas novas raças, SPBl:10 (63/31/02/00) e SPBl:11 (63/63/18/00). Em 2013, uma nova codificação foi determinada (63/31/18/00), à qual propôs a denominação de SPB1:12. Os genes Dm-14 e Dm-15, e os fatores de resistência FR-17, FR-18, FR-36, FR-37 e FR-38 conferem resistência a essas novas raças identificadas. Recomenda-se, portanto, em programas de melhoramento genético de alface, a utilização dos fatores FR-17, FR-18 e FR-38 como fontes de resistência para novas cultivares desenvolvidas para cultivo no Estado de São Paulo, por conferirem resistência a todas as 12 raças já identificadas.

Palavras-chave: Bremia lactucae. genes Dm, Lactuca sativa L., resistência de plantas à doenças.

\section{ABSTRACT}

Nunes, R.C.; Castoldi, R.; Gomes, R.F.; Tobar-Tosse, D.E.; Braz, L.T. Survey of races of the causal agent of downy mildew of lettuce in the state of São Paulo in 2012 and 2013. Summa Phytopathologica, v.42, n.1, p.53-58, 2016.

Lettuce is, among leafy vegetables, the most economically important one to Brazil. In the winter, at low temperatures and under leaf wetness, downy mildew of lettuce, a disease caused by the etiologic agent Bremia lactucae, occurs in almost all regions where this vegetable is grown and is considered one of the most severe foliar diseases for the culture. The aim of this study was to identify the races of B. lactucae in 2012 and 2013 that occurred in the main producing regions of São Paulo State, such as: Ribeirão Preto, Jaboticabal, Pirangi, Catanduva, São José do Rio Preto, Atibaia, Salesópolis, Biritiba Mirim, Mogi das Cruzes, Campinas, Itapira, Mogi Mirim, Cândido Mota, Presidente Prudente, Echaporã, Assis, Marilia, Botucatu and Bauru. During the months of July / August 2012 and 2013, we collected samples of lettuce leaves showing symptoms of downy mildew, and in each collected sample the pathogen structures referred to an isolate. The sporangia were multiplied on the susceptible cultivar Solaris, with subsequent inoculation in differential cultivars, performing evaluations on the $12^{\text {th }}$ day from the appearance of the first sporulation in the susceptible cultivar 'Green Tower' (Dm-0), according to the code "Sextet". In 2012, two new codes were determined, identifying two new races, SPB1:10 (63/31/02/00) and SPB1:11 (63/63/18/00). In 2013, a new codification was determined (63/31/18/00), to which the name SPB1:12 was proposed. The genes Dm-14 and Dm-15 and the resistance factors FR-17, FR-18, FR-36, FR-37 and FR-38 confer resistance to these new races that were identified. It is recommended, therefore, in breeding programs of lettuce, the use of factors FR-17, FR-18 and FR-38 as sources of resistance for new cultivars developed in the state of São Paulo, because they confer resistance to all 12 already identified races.

Keywords: Bremia lactucae, genes Dm, Lactuca sativa L., resistance of plants to disease.

A alface (Lactuca sativa L.) pertence à família Asteraceae e ao gênero Lactuca, no qual são descritas mais de 100 espécies. Esta hortaliça folhosa é considerada a mais popular do mundo, destacandose pelo elevado teor de sais minerais e de vitaminas $A, B_{1}, B_{2}$ e C, além de conter cálcio e ferro.

Dados do Agrianual (1), referente ao ano de 2013, mostram que foram comercializadas 52.408 toneladas de alface no Estado de São Paulo, destacando a região do Cinturão Verde como a área de maior produção (6). No entanto, áreas menores dessa cultura distribuem-se por todo o Estado, ao redor das principais cidades, sendo que estas têm sido expandidas gradativamente com o decorrer dos anos (5).

A evolução de cultivares e sistemas de manejo, tratos culturais, irrigação, espaçamentos, técnicas de colheita, conservação pós-colheita e mudanças nos hábitos de alimentação impulsionaram o cultivo, tornando a alface a hortaliça folhosa mais consumida no país (10).

Apesar das extensas áreas de produção, o cultivo de alface apresenta 
limitações, principalmente em virtude de sua sensibilidade às condições adversas de temperatura e umidade, acarretando na ocorrência de diversos fitopatógenos, dentre eles a Bremia lactucae Regel, causadora do míldio em alface.

O míldio é uma doença de distribuição mundial e é tido como uma das mais importantes e severas da cultura, devido seu alto poder destrutivo, tanto em casa de vegetação como em campo (15). O sintoma da doença inicia-se com a formação de pequenas manchas angulares, de coloração verde-clara a amarelada, na face superior da folha. Com o seu desenvolvimento, a coloração da parte infectada torna-se marrom e, sob condições de alta umidade, o fitopatógeno forma frutificações brancas na face inferior das folhas (9).

O ciclo da doença é do tipo policíclico, assim, a redução do inóculo inicial apresenta efeito limitado no desenvolvimento máximo da doença, uma vez que a progressão geométrica de multiplicação de novas infecções resulta em rápido aumento da doença em sua fase crítica (13).

Van Ettekoven \& Van Der Arend (14), com o intuito de uniformizar o sistema de identificação de raças de míldio, utilizaram códigos para cada raça, denominados "Sextet Codes" evitando, dessa forma, que uma mesma raça recebesse denominações diferentes em distintas regiões do mundo.

Braz et al. (3) em estudos pioneiros de identificação de raças realizados no Estado de São Paulo, nos anos de 2003 e 2004, identificaram a primeira raça de B. lactucae, denominada SPB1:01. Souza et al. (11), nos anos de 2006 e 2007, identificaram três novas raças, sendo elas: SPB1:02, SPB1:03 e SPB1:04. Em 2008 e 2009, Castoldi et al. (4) verificaram o surgimento de outras duas novas raças, SPB1:05 e SPB1:06. Gallati et al. (5) identificaram três novas raças, nos anos de 2010 e 2011, sendo elas SPB1:07, SPB1:08 e SPB1:09.

Devido à ampla variabilidade genética de $B$. lactucae, a introdução ou a mutação de novos genes podem ocasionar o aparecimento de novas raças com todos os genes de virulência, capazes de vencer a resistência das cultivares comerciais resistentes. Sendo assim, o conhecimento das raças que ocorrem anualmente em diferentes regiões é de grande valia, pois pode auxiliar a escolha de cultivares resistentes para plantio, bem como direcionar os programas de melhoramento para a obtenção de cultivares com resistência a novas raças.

Diante do exposto, objetivou-se com este trabalho identificar as raças de B. lactucae, de ocorrência nos principais municípios produtores de alface do Estado de São Paulo, nos anos de 2012 e 2013.

\section{MATERIAL E MÉTODOS}

Durante os meses de julho e agosto dos anos de 2012 e 2013, foram coletadas, respectivamente, 49 e 45 amostras de folhas de alface com sintomas de míldio, sendo as estruturas do patógeno em cada amostra coletada referidas como um isolado (Figura 1).

As coletas foram realizadas em diferentes municípios produtores de alface: como: Ribeirão Preto, Jaboticabal, Pirangi, Catanduva, São José do Rio Preto, Atibaia, Salesópolis, Biritiba Mirim, Mogi das Cruzes, Campinas, Itapira, Mogi Mirim, Cândido Mota, Presidente Prudente, Echaporã, Assis, Marília, Botucatu e Bauru. Em 2012 não foram encontradas plantas com esporângios do fitopatógeno nos municípios de Pirangi, Cândido Mota e Salesópolis e em 2013, o mesmo ocorreu nos municípios de São José do Rio Preto, Salesópolis, Pirangi, Cândido Mota, Presidente Prudente, Assis, Marília e Echaporã.

As amostras foram armazenadas em recipientes plásticos de $50 \mathrm{~mL}$, identificados com o município da coleta, nome do produtor, nome da propriedade e nome da cultivar, e acondicionadas em caixas térmicas

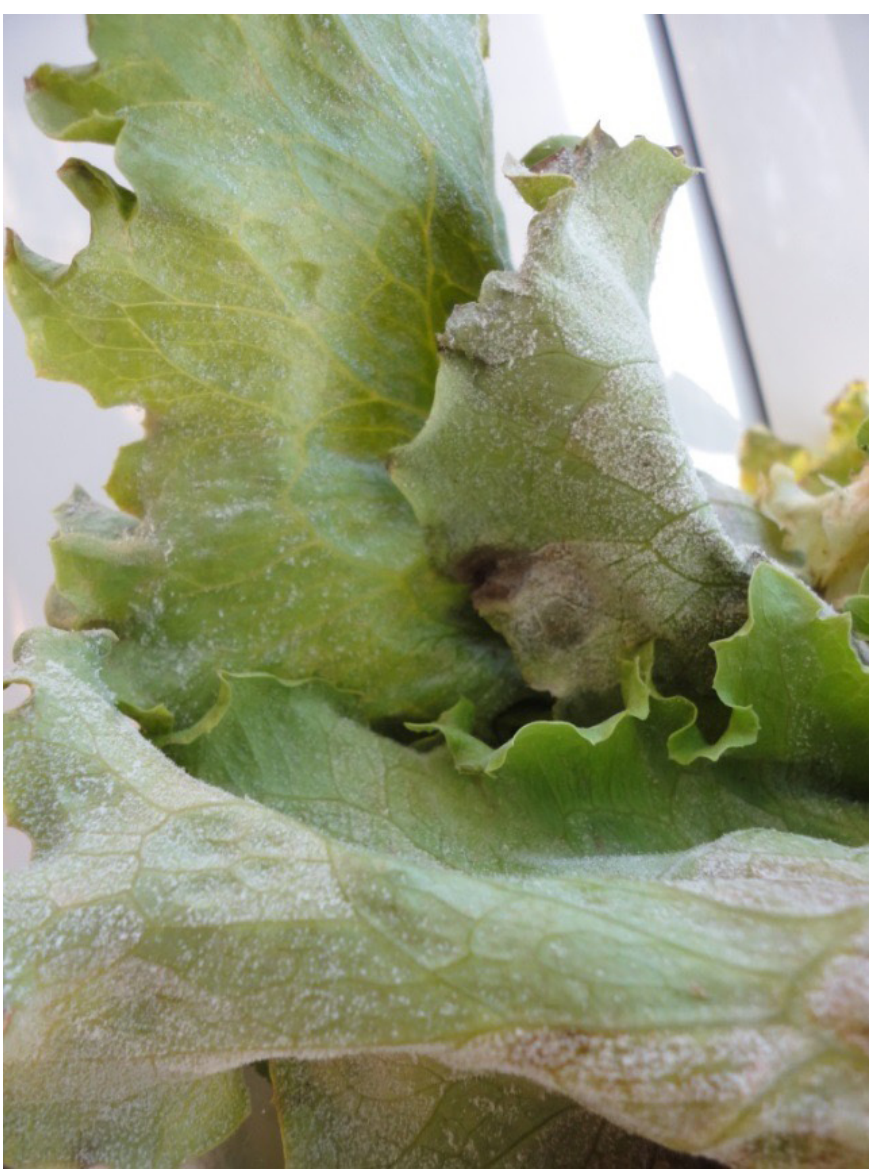

Figura 1. Folhas de alface com sintomas de Bremia lactucae.

para o transporte até o Laboratório de Genética e Melhoramento de Hortaliças, do Departamento de Produção Vegetal (UNESP-FCAV).

Ao término das coletas, realizou-se a multiplicação dos esporângios, para obtenção de quantidades suficientes de inóculo para utilização no teste de diferenciação. Neste procedimento, sementes da cultivar suscetível Solaris foram semeadas em caixas plásticas gerbox (11 x 11 x $3,5 \mathrm{~cm}$ ), forradas com papel germitex umedecido, dividido em duas partes iguais, sendo que em cada parte foram semeadas aproximadamente 20 sementes, totalizando uma caixa por amostra. Estas foram mantidas por 15 dias em câmara de incubação tipo BOD (Biochemical Oxygen Demand) com temperatura de $13^{\circ} \mathrm{C}$ e fotoperíodo de $12 \mathrm{~h}$. Transcorrido esse período, foi realizada a inoculação dos esporângios nas plântulas. Após 15 dias, foram utilizadas como fonte de inóculo para a próxima semeadura. Este procedimento repetiu-se por três vezes, seguindo ordem de semeadura e inoculação, até obter quantidades suficientes de esporângios.

Obtidas as quantidades suficientes de esporângios, sementes das 20 cultivares diferenciadoras de alface foram semeadas de forma equivalente ao procedimento de multiplicação, porém, o papel germitex foi dividido em quatro partes iguais. Em cada uma das partes foram semeadas aproximadamente 40 sementes de cada cultivar diferenciadora.

As cultivares diferenciadoras foram divididas em quatro grupos, sendo atribuídos valores de 1, 2, 4, 8, 16 e 32 a cada cultivar, dentro de cada grupo, segundo a metodologia de Van Ettekoven \& Der Arend (14), como segue: Grupo I: Lendnicky (1); UCDm-2 (2); Dandie (4); R4T57D (8); Valmaine (16); Sabine (32); Grupo II: LSE 57/15 (1); UCDm-10 (2); Captan (4); Hilde II (8); Pennlake (16); UCDm-14 (32); Grupo III: Num Dm 15 (1); CG Dm-16 (2); Num Dm 17 (4); Colorado (8); Ninja 
Tabela 1. Resposta de resistência/suscetibilidade de cultivares diferenciadoras à Bremia lactucae para os isolados coletados durante o ano de 2012. Jaboticabal-SP, UNESP-FCAV.

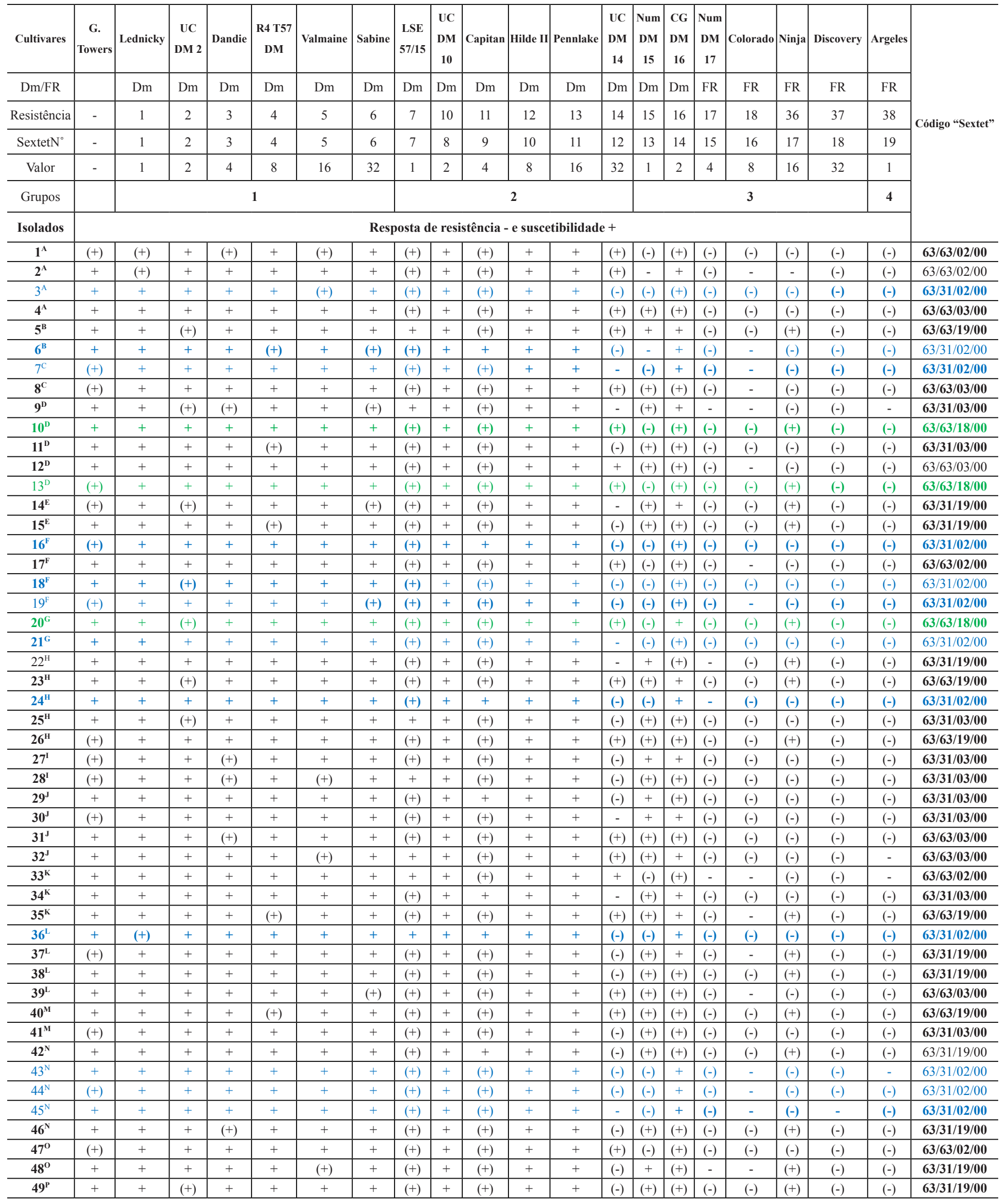

Região de coleta dos isolados: A- Ribeirão Preto; B- Catanduva; C- São José do Rio Preto; D-Botucatu; E- Bauru; F- Jaboticabal; G- Mogi Mirim; H- Itapira; I- Atibaia; J- Campinas; K- Biritiba Mirim; L- Mogi das Cruzes; M- Presidente Prudente; N- Assis; O- Echaporã e P- Marília. Azul: raça SPBl:10 identificada em 2012. Verde: raça SPBl:11 identificada em 2012. 
(16); Discovery (32); Grupo IV: Argeles (1).

Após semeadura das cultivares diferenciadoras, estas foram mantidas por 15 dias em câmara de incubação tipo BOD à temperatura de $13^{\circ} \mathrm{C}$ e fotoperíodo de $12 \mathrm{~h}$. Após esse período, realizou-se a inoculação dos isolados de B. lactucae nas plântulas das cultivares diferenciadoras, de acordo com a metodologia de Ilott et al. (7), utilizando esporângios retirados de tecidos infestados do hospedeiro com auxílio de água destilada. A suspensão inoculada foi na concentração de $5 \times 10^{4}$ esporângios $\mathrm{mL}^{-1}$, sendo pulverizada nas plântulas até o ponto de escorrimento.

Após a inoculação, as caixas foram recolocadas em BOD com temperatura de $13^{\circ} \mathrm{C}$, sendo que durante as seis primeiras horas, permaneceram em câmara escura e, após esse tempo, o fotoperíodo foi ajustado para 12 horas.

O monitoramento ocorreu diariamente e quando houve aparecimento da primeira esporulação nas plântulas da cultivar suscetível 'Green Towers' (Dm-0) no $12^{\circ}$ dia, iniciaram-se as avaliações. As cultivares diferenciadoras foram avaliadas individualmente, verificando-se a presença ou não de esporulação e de necrose, conforme metodologia proposta por Van Ettekoven \& Der Arend (14). Essa metodologia baseiase na escala de sinais $+,(+),-$ ou (-), de acordo com a porcentagem de níveis de danos nos tecidos vegetais de alface, sendo identificado como '+' quando mais de $80 \%$ das plântulas apresentarem lesões esporulantes; (+): quando mais de $80 \%$ das plântulas apresentarem pontos necróticos e com muitas lesões esporulantes; -: quando menos de $5 \%$ das plântulas apresentarem lesões esporulantes; e (-): quando as plântulas apresentarem pontos necróticos e com poucas lesões esporulantes.

As diferenciadoras que se mostraram suscetíveis a determinado isolado coletado tiveram seus valores somados dentro de cada grupo (1 a 4). O somatório de cada grupo foi separado por uma barra, sendo essa sequência numérica chamada de "Código Sextet", o qual é comparado com sequências numéricas já determinadas. Caso esta seja diferente daquelas já conhecidas, significa tratar-se de uma nova raça.

\section{RESULTADOS E DISCUSSÃO}

Em 2012, foram determinadas duas novas codificações de $B$. lactucae nas regiões produtoras do Estado de São Paulo pelo código "Sextet" 63/31/02/00 e 63/63/18/00, originando duas novas raças do fitopatógeno, SPB1:10 e SPB1:11, respectivamente (Tabela 1).

Dos 49 isolados avaliados em 2012, foram determinadas cinco codificações de B. lactucae já verificadas anteriormente por Souza et al. (11), Castoldi et al. (4) e Galatti et al. (5), todos no Estado de São Paulo: 63/31/19/00, 63/63/19/00, 63/63/03/00, 63/63/02/00 e 63/31/03/00.

Avaliando-se os resultados, nota-se que o novo "Código Sextet" $63 / 31 / 02 / 00$, referente à raça $\mathrm{SPB1}: 10$, ocorre em grande parte dos isolados de alface coletados no ano de 2012 (24,48\%) (Tabela 2), com exceção de Atibaia, Bauru, Biritiba Mirim, Botucatu, Campinas, Echaporã, Marília e Presidente Prudente.

Apesar da grande ocorrência, esta nova raça não quebra a resistência dos genes Dm-14, Dm-15, FR-17, FR-18, FR-36, FR-37 e FR-38, diferindo das raças SPB1:01; SPB1:02; SPB1:03; SPB1:04; SPB1:05, SPB1:06, SPB1:07, SPB1:08 e SPB1:09 respectivamente, pela resistência dos genes Dm-14, Dm-15, FR-36 e FR-37; Dm-15 e FR-36; Dm-14, Dm-15 e FR-36; Dm-14 e Dm-15; Dm-14, Dm-15, Dm-16 e FR-37; Dm-14; Dm-15; Dm-6, Dm-14, Dm-15, FR-36 e FR-37; Dm-6, Dm-14, Dm-15 e FR-36.

Tabela 2. Porcentagem de ocorrência das raças de Bremia lactucae no ano de 2012 nos municípios produtores de alface do Estado de São Paulo. Jaboticabal-SP, UNESP-FCAV.

\begin{tabular}{lll}
\hline $\begin{array}{l}\text { Raças identificadas } \\
\text { Coleta 2012 }\end{array}$ & $\begin{array}{l}\text { Frequência } \\
(\%)\end{array}$ & Municípios da coleta \\
\hline SPB1: 02 (63/31/19/00) & 18,36 & Bauru, Itapira, Assis, Echaporã, Marília e Mogi das Cruzes \\
SBP1: 03 (63/63/19/00) & 10,20 & Catanduva, Itapira, Biritiba Mirim e Presidente Prudente \\
SBP1: $04(63 / 63 / 03 / 00)$ & 12,24 & Ribeirão Preto, São José do Rio Preto, Botucatu, Campinas e Mogi das Cruzes \\
SBP1: $06(63 / 63 / 02 / 00)$ & 10,20 & Ribeirão Preto, Jaboticabal, Biritiba Mirim e Echaporã \\
SBP1: $07(63 / 31 / 03 / 00)$ & 18,36 & Botucatu, Itapira, Atibaia, Campinas e Biritiba Mirim \\
SBPl: $10(63 / 31 / 02 / 00)^{1}$ & 24,48 & Ribeirão Preto, Itapira, Assis, Catanduva, São José do Rio Preto, Jaboticabal, Mogi Mirime Mogi das Cruzes \\
SBP1: $11(63 / 63 / 18 / 00)^{1}$ & 6,12 & Mogi Mirim e Botucatu \\
\hline
\end{tabular}

${ }^{1}$ Raças identificada em 2012.

Tabela 3. Porcentagem de ocorrência das raças de Bremia lactucae no ano de 2013 nos municípios produtores de alface do Estado de São Paulo. Jaboticabal-SP, UNESP-FCAV.

\begin{tabular}{lll}
\hline Raças identificadas & $\begin{array}{l}\text { F requên cia } \\
\text { Coleta } 2013\end{array}$ & Municípios da coleta \\
\hline SPBl: $02(63 / 31 / 19 / 00)$ & 11,11 & Botucatu, Bauru, Jaboticabal, Itapira, e Mogi das Cruzes \\
SBP1: $03(63 / 63 / 19 / 00)$ & 13,33 & Ribeirão Preto, Catanduva, Itapira e Biritiba Mirim \\
SBPl: $04(63 / 63 / 03 / 00)$ & 13,33 & Catanduva, Bauru, Campinas e Mogi das Cruzes \\
SBPl: $06(63 / 63 / 02 / 00)$ & 8,88 & Ribeirão Preto e Jaboticabal \\
SBPl: $07(63 / 31 / 03 / 00)$ & 20,00 & Catanduva, Botucatu, Bauru, Mogi Mirim, Atibaia e Campinas \\
SBPl: $10(63 / 31 / 02 / 00)$ & 15,55 & Ribeirão Preto, Botucatu, Jaboticabal, Mogi Mirim, Itapira e Mogi das Cruzes \\
SBPl: $12(63 / 31 / 18 / 00)^{1}$ & 17,77 & Botucatu, Bauru, Mogi Mirim, Campinas e Mogi das Cruzes \\
\hline
\end{tabular}

\footnotetext{
${ }^{1}$ Raça identificadas em 2013.
} 
Tabela 4. Resposta de resistência/suscetibilidade de cultivares diferenciadoras à Bremia lactucae para os isolados coletados durante o ano de 2013. Jaboticabal-SP, UNESP-FCAV.

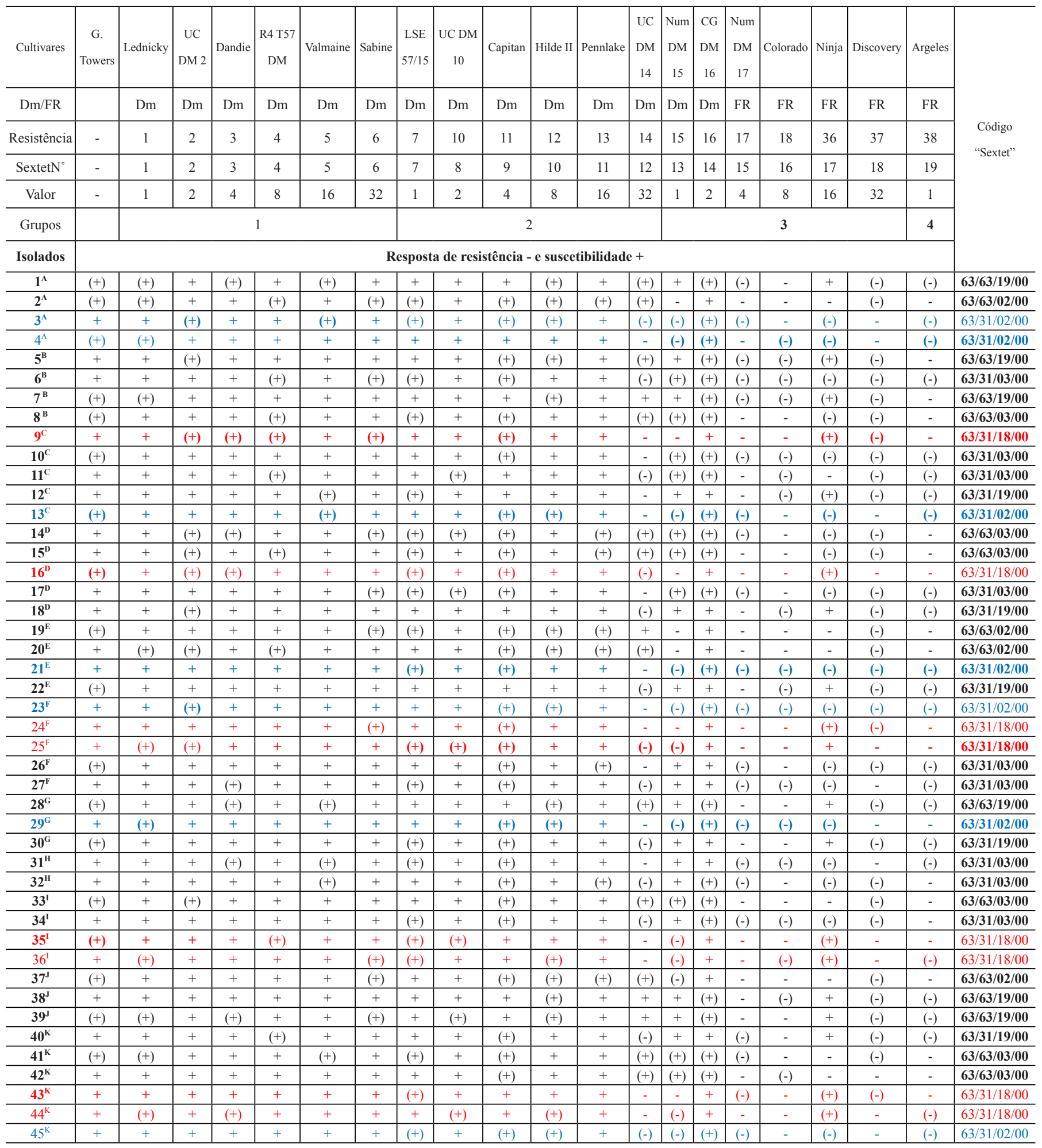

Região de coleta dos isolados: A- Ribeirão Preto; B- Catanduva; C- Botucatu; D-Bauru; E- Jaboticabal; F- Mogi Mirim; G- Itapira; H- Atibaia; I- Campinas; J- Biritiba Mirim e K- Mogi das Cruzes. Azul: raça SPBl:10 identificada em 2012. Vermelho: raça SPBl:12 identificada em 2013. 
As novas raças SPB1:10 e SPBl:11 não diferem em relação aos genes de resistência da planta quando comparado as raças anteriormente identificadas, porém, diferem entre si com relação ao gene Dm-14 e ao fator de resistência FR- 36 .

Em 2013, dos 45 isolados avaliados, foram encontrados sete códigos: 63/31/19/00, 63/63/19/00, 63/63/03/00, 63/63/02/00,63/31/03/00, $63 / 31 / 02 / 00$ e $63 / 31 / 18 / 00$ com frequência, respectivamente, de $11,11 \%$, $13,33 \%, 13,33 \%, 8,88 \%, 20,00 \%, 15,55 \%$ e $17,77 \%$ (Tabelas 3 e 4 ).

Avaliando os resultados, observa-se que o "Código Sextet" 63/31/18/00 ocorreu em grande parte dos municípios produtores de alface do Estado de São Paulo (Botucatu, Bauru, Mogi Mirim, Campinas e Mogi das Cruzes), podendo ser considerado uma nova raça, à qual se propõe a denominação de SPBl:12. Assim como as novas raças determinadas em 2012, esta nova raça não quebra a resistência dos genes, uma vez que, de acordo com os resultados de resposta de resistência/ suscetibilidade, aos genes Dm-14 e 15, e aos fatores de resistência FR$17,18,37$ e 38 conferem resistência à esta nova raça.

Além disso, nota-se que a raça SPBl:07 (63/31/03/00), assim como em 2012, apresentou ocorrência relativamente alta em 2013 (20,00\%), indicando a permanência desta raça nos municípios produtores de alface do Estado de São Paulo e, consequentemente, a necessidade de controle.

Verifica-se também, que a raça SPBl:11, estabelecida pelo código 63/63/33/00 e detectada em 2012, não apareceu entre os isolados coletados em 2013. No entanto, nos municípios de ocorrência desta raça (Mogi Mirim e Botucatu) houve o surgimento da nova raça denominada SPB1:12 (63/31/18/00). Este fato evidencia a necessidade de monitoramento dos municípios produtores de alface, com o intuito de identificar a presença de novas raças e desenvolver cultivares com genes de resistência.

Segundo Borém e Miranda (2), é provável que o surgimento de novas raças ocorra devido a mecanismos criadores de novas combinações de genes, denominados mutações. Além disso, pode ocorrer recombinação gênica, ou seja, a troca de genes entre duas moléculas de DNA, aumentando a variabilidade genética de uma população, podendo ser a explicação do constante surgimento de novas raças no decorrer dos anos.

$\mathrm{Na}$ ausência de recombinação, a variabilidade genética é relativamente baixa, acarretando menor surgimento de raças, no entanto, esta baixa frequência torna-se suficiente para causar perdas econômicas, pois apesar do míldio ocorrer somente nas folhas, interferindo principalmente na fotossíntese, a doença pode tornar-se sistêmica, infectando internamente caule e colonizando até mesmo raízes. Lesões velhas tornam-se necróticas e os tecidos são invadidos por patógenos secundários, como, por exemplo, o fungo Botrytis cinerea Pers., o qual pode causar danos à cultura no campo e, consequentemente, na comercialização desta hortaliça folhosa (8).

Valade (12) estudando populações francesas de B. lactucae, observou condições reprodutivas do fitopatógeno semelhantes às condições do Brasil, ou seja, a forma assexuada de reprodução. No entanto, não é rejeitada a hipótese de que esteja ocorrendo eventos de recombinação sexual nas populações francesas, uma vez que constatou-se ambos tipos de reprodução, porém a forma sexuada apresentou menor taxa. No Brasil, este evento de recombinação sexual ainda não foi verificado, o que justifica o baixo número de raças identificadas no Estado de São Paulo quando comparado aos países europeus e norte-americanos.

Semelhante aos resultados encontrados em 2010 por Galatti et al.(5), as raças SPBl:02 (63/31/19/00) e SPB1:07 (63/31/03/00) apresentaram grandes ocorrências no ano de 2012, no entanto, as raças SPBl:01, SPB1:05, SPB1:08 e SPB1:09 identificadas por Braz et al. (3), Castoldi et al. (4) e Galatti et al. (5), embora tenha ocorrido em alta frequência nos anos anteriores, não foram relatadas nos levantamentos de 2012 e 2013. Isso pode ser devido às diferentes pressões de seleção nos distintos anos de coletas, causada pelo uso intensivo de fungicidas que podem resultar na seleção de patógenos resistentes em curto período de tempo (5), bem como a alteração das cultivares utilizadas.

Além disso, variações climáticas ao longo dos anos podem influenciar na frequência de aparecimento das raças, uma vez que a temperatura e a umidade atmosférica estão entre os principais fatores ambientais que influenciam a esporulação do patógeno, podendo ser a causa das oscilações no decorrer dos anos.

\section{AGRADECIMENTOS}

À FAPESP (Fundação de Amparo e Pesquisa do Estado de São Paulo), pelo Auxílio Financeiro à Pesquisa Regular, processo $\mathrm{n}^{\circ}$ 2012/09705-4 e pela bolsa concedida à primeira autora, processo $\mathrm{n}^{\circ}$ 2012/15703-4.

\section{REFERÊNCIAS}

1. AGRIANUAL. Anuário da agricultura brasileira. São Paulo: FNP -Consultoria e Agroinformativo, São Paulo, v. 1, p.127, 2015.

2. Borém, A.; Miranda, G.V. Melhoramento de plantas. 6.ed. Viçosa: Editora UFV, 2013.

3. Braz, L.T.; Dalpian, T.; Pissardi, M.A. Identification of races of Bremia lactucae in São Paulo, Brazil. Acta Horticulturae, Seoul, v.760, p.317-321, 2007.

4. Castoldi, R.; Charlo, H.C.O.; Dalpian, T.; Melo, D.M.; Botelho, A.P.; Braz, L.T. Identification of new Bremia lactucae races in lettuce in São Paulo state. Horticultura Brasileira, Brasília, DF, v.30, p.209-213, 2012.

5. Galatti, F. D. S., Castoldi, R., Braz, L. T., \& Panizzi, R. D. C. Monitoramento de raças de Bremia lactucae em 2010 e 2011 no Estado de São Paulo. Summa Phytopathologica, Botucatu, SP, v.38: 271-279, 2012.

6. IEA. Instituto de Economia Agrícola. Área e produção dos principais produtos da agropecuária. São Paulo, 2012. Disponível em: $<$ http://ciagri. iea.sp.gov.br/bancoiea/subjetiva.aspx?cod_sis $=1 \&$ idioma $=1>$. Acesso em: $02 / 10 / 2014$.

7. Ilott, T.W.; Durgan, M.E., Michelmore, R.W. Genetics of virulence in Calia fornia populations of Bremia lactucae (Lettuce Downy Mildew). Phytopa€ thology, Saint Paul, v.77, n.10, p.1381-1386, 1987.

8. Padgett-Johson, M.; Laemmlen, F. Downy mildew of lettuce (Bremia lactucae): biology, disease symptoms and damage. Using the down mildew index model for disease management. Sacramento, CA: Departament of Pesticide Regulation, 2009. Disponível em: < http://ucce.ucdavis.edu/files/ filelibrary/2028/23067.pdf>. Acesso em: 02/10/2013

9. Persley, D. Diseases of vegetable crops. Queensland: Department of Primary Industries, p.164, 1994.

10. Resende, F.V.; Saminêz, T.C.O; Vidal M.C.; Sousa, R.B.; Clemente, F.M.V. Cultivo de alface em sistema orgânico de produção. Brasília, DF: Embrapa (Circular Técnica 56), 2007.

11. Souza, J.O; Dalpian, T; Braz, L.T; Camargo, M. Novas raças de Bremia lactucae, agente causador do míldio da alface, identificadas no estado de São Paulo. Horticultura Brasileira, Brasília, DF, v.29, n.3, p.282-286, 2011.

12. Valade, R. Potentiel évolutif et adaptation des populations de l>agent du mildiou de la laitue, Bremia lactucae, face auxpressions de sélection de la plante hôte, Lactuca sativa. 2012. 173f. Thèse (Docteur en Sciences) Universite Paris Sud, Paris.

13. Vale, F.X.R.; Jesus, W.C.; Liberato, J.R.; Souza, C.A. Natureza das epidemias. In: Vale, F.X.R.; Jesus, W.C.; Zambolim, L. Epidemiologia aplicada ao manejo de doenças de plantas. p. 21-46, 2004.

14. Van Ettekoven, K.; Van Der Arend, A. Identification and denomination of "new" races of Bremia lactucae. In: Eucarpia Meeting on Leafy Vegetables Genetics and Breeding, 1999, Olomuc. Proceeding. Olomuc: Palacky Unim versity, 1999. p. $105-107$. .

15. Zabolim, L.; Vale, F.X.R.; Costa, H. Controle de doenças de plantas-hortaliças. Viçosa: Editora UFV, 2000. v.1, 444p. 